\title{
Simulation Study of Acoustic Wave Propagation in Ocean
}

\author{
T. B. Mohite-Patil \\ Lecturer (Sel.Gr.) \\ D.Y.Patil Engineering \\ College, \\ Kolhapur, India
}

\author{
A.K.Saran \\ Scientist \\ NIO, Goa, \\ India.
}

\author{
S. R. Sawant \\ Professor and Head \\ Shivaji University, \\ Kolhapur, India.
}

\author{
R. H.Chile \\ Professor \\ Guru Govind College \\ of Engg. \\ Nanded, India.
}

\author{
T. T. Mohite-Patil \\ Vice-Principal \\ Sanjeevan Engg \\ College, \\ Kolhapur, India.
}

\begin{abstract}
Many reports are available on the sound attenuation and speed in the deep ocean, as a function of different ingredients of sea. The absorption and speed of sound waves are related to the change in sound speed, depth, salinity, temperature, $\mathrm{PH}$, pressure and frequency. Five different simulation models have been developed to determine sound speed in sea water by inputting the sea water parameter data. It is observed that in all the models, except Chen and Millero model, the speeds evaluated using the simulation models match satisfactorily with the observed speed of sound in sea water. Deviation exists and it tends to increase with the depth. The errors from different models are within acceptable margin except for the Chen and Millero model. The Mackenzie Equation model gives least error.
\end{abstract}

\section{Keywords}

Sound absorption; Simulation model; Salinity; Temperature; Pressure; Sound Speed; Depth; Frequency; Mathematical formulae..

\section{INTRODUCTION}

Simulink is an integrated toolset of MATLAB package useful for modeling, simulating, and analyzing dynamic systems ${ }^{[1]}$. It supports linear and nonlinear systems, modeled in continuous time, discrete time, or a combination of the two. Simulink allows quick access to all the analysis tools of MATLAB enabling the results to be acquired, analyzed and visualized. It provides a graphical user interface (GUI) for building model block diagrams. Simulink includes a comprehensive library of electronics system building blocks viz. sink/source modules, linear and nonlinear components, and connectors to name a few. In this article the simulink approach to develop the various models of acoustical wave propagation in sea water using different empirical formulae given by many workers has been detailed. ${ }^{[1-6,11,]}$ We have developed simulation models using the empirical formulae developed by different researchers. The simulation results of the speed and practically observed values are compared and the corresponding errors are estimated. It is observed that the values of the speed furnished by these models are nearly accurate.

\section{SIMULATION MODEL}

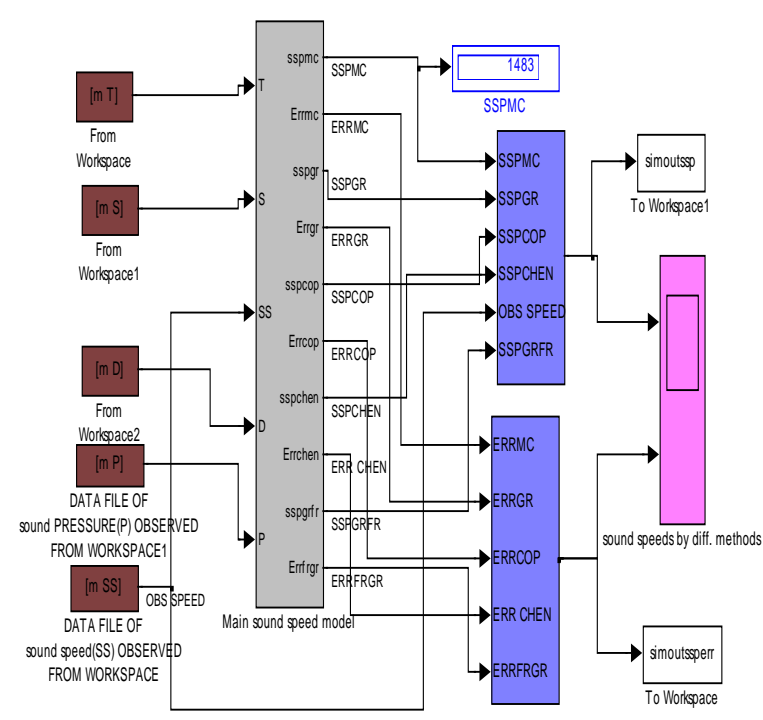

Fig.1. Main simulation model of sound speed and error calculations

Fig.1 shows the main simulation model designed using simulink toolbox of MATLAB ${ }^{[1]}$ to determine the sound speed in the sea water .The input data like depth, salinity, temperature, and pressure which modulate the sound speed have been read from workspace through the simin block in the simulink library. The empirical formulae proposed by different investigators have been used to calculate the speed. Each subsystem has been designated by the name of the investigator e.g. Mackenzie method ${ }^{[4]}$,Del Grosso's method $^{[2]}$, Chen Millero method ${ }^{[3]}$, and Copen's method ${ }^{[4]}$. The error in the calculated speed of sound in sea water and observed speed has also been calculated from these models. The exhaustive model showing the different methods used is shown in fig. 2 . 


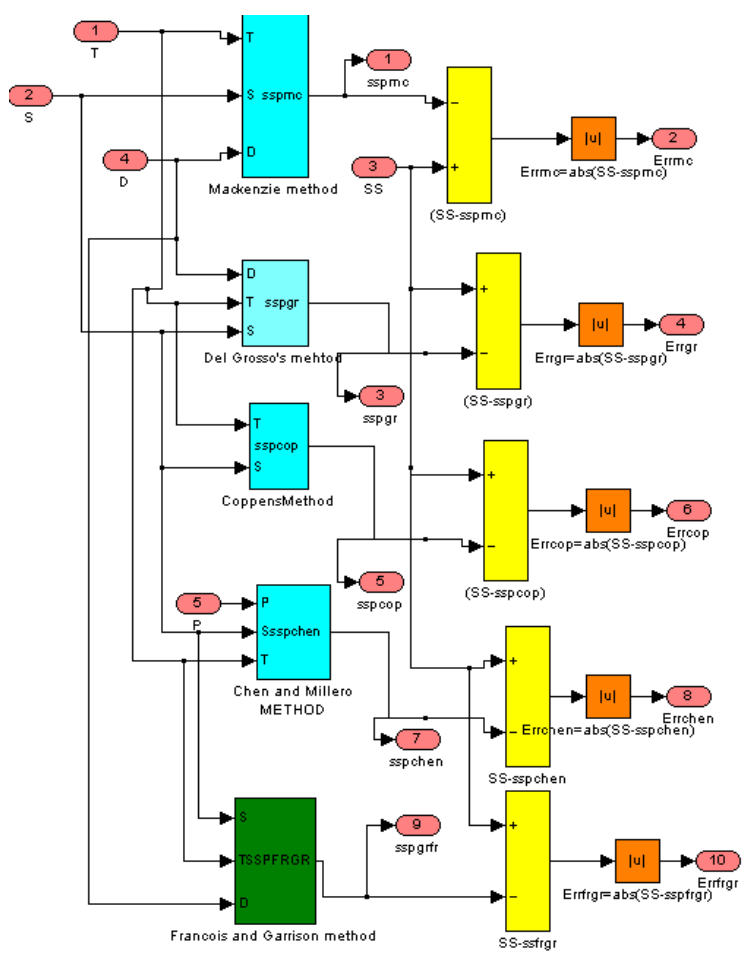

Fig.2 Sub Simulation model for sound speed showing different types of sound speed simulations

2.1 Mackenzie Equation The equation to determine the speed of sound in sea-water as a function of temperature, salinity and depth proposed by Mackenzie ${ }^{(4)}$ is given by the following equation and it's simulation model is shown in fig3.

$\mathrm{C}(\mathrm{D}, \mathrm{S}, \mathrm{T})=1448.96+4.591 \mathrm{~T}-5.304 \times 10^{-2} \mathrm{~T}^{2}+2.374 \times 10^{-}$ ${ }^{4} \mathrm{~T}^{3}+1.340(\mathrm{~S}-35)+1.630 \times 10^{-2} \mathrm{D}+1.675 \times 10^{-7} \mathrm{D}^{2}-1.025 \mathrm{x}$ $10^{-2} \mathrm{~T}(\mathrm{~S}-35)-7.139 \times 10^{-13} \mathrm{TD}^{3}$

$\mathrm{T}=$ temperature ${ }^{0} \mathrm{C} \mathrm{S}=$ salinity in parts per thousand $\mathrm{D}=$ depth in meters Range of validity: temperature 2 to $30{ }^{\circ} \mathrm{C}$, salinity 25 to 40 parts per thousand, depth 0 to $8000 \mathrm{~m}$.

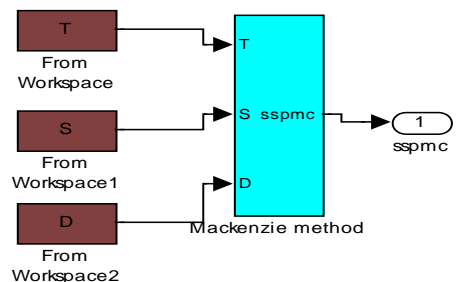

Fig.3. Main Simulation model subsystem for sound speed in the sea water based on Mackenzie equation

\subsection{Del Grosso's Method ${ }^{[2]}$}

An alternative equation to the UNESCO algorithm ${ }^{(3)}$, which has a more restricted range of validity, but which is preferred by some authors, is the Del Grosso's equation.

$$
\begin{aligned}
\mathrm{C}(\mathrm{S}, \mathrm{T}, \mathrm{P}) & =\mathrm{C}_{000}+\mathrm{C}_{\mathrm{T}}+\mathrm{C}_{\mathrm{S}}+\mathrm{C}_{\mathrm{P}}+\mathrm{C}_{\mathrm{STP}} \\
\mathrm{C}_{\mathrm{T}}(\mathrm{T}) & =\mathrm{C}_{\mathrm{T} 1} \mathrm{~T}+\mathrm{C}_{\mathrm{T} 2} \mathrm{~T}^{2}+\mathrm{C}_{\mathrm{T} 3} \mathrm{~T}^{3} \\
\mathrm{C}_{\mathrm{S}}(\mathrm{S}) & =\mathrm{C}_{\mathrm{S} 1} \mathrm{~S}+\mathrm{C}_{\mathrm{S} 2} \mathrm{~S}^{2}
\end{aligned}
$$

$$
\mathrm{C}_{\mathrm{P}}(\mathrm{P})=\mathrm{C}_{\mathrm{P} 1} \mathrm{P}+\mathrm{C}_{\mathrm{P} 2} \mathrm{P}^{2}+\mathrm{C}_{\mathrm{P} 3} \mathrm{P}^{3}
$$

$\mathrm{C}_{\mathrm{STP}}(\mathrm{S}, \mathrm{T}, \mathrm{P})=\mathrm{C}_{\mathrm{ST}} \mathrm{ST}+\mathrm{C}_{\mathrm{TP}} \mathrm{TP}+\mathrm{C}_{\mathrm{TP} 2} \mathrm{TP}^{2}+\mathrm{C}_{\mathrm{T} 3 \mathrm{P}} \mathrm{T}^{3} \mathrm{P}+$ $\mathrm{C}_{\mathrm{T} 2 \mathrm{P} 2} \mathrm{~T}^{2} \mathrm{P}^{2}+\mathrm{C}_{\mathrm{TP} 3} \mathrm{TP}^{3}+\mathrm{C}_{\mathrm{ST} 2} \mathrm{ST}^{2}+\mathrm{C}_{\mathrm{STP}} \mathrm{STP}+\mathrm{C}_{\mathrm{S} 2 \mathrm{TP}} \mathrm{S}^{2} \mathrm{TP}+$ $\mathrm{C}_{\mathrm{S} 2 \mathrm{P} 2} \mathrm{~S}^{2} \mathrm{P}^{2}$

$\mathrm{T}=$ temperature in degrees Celsius $\mathrm{S} \quad$ = salinity in Practical Salinity Units $\mathrm{P} \quad=$ pressure in $\mathrm{kg} / \mathrm{cm}^{2}$

Range of validity: temperature 0 to $30{ }^{\circ} \mathrm{C}$, salinity 30 to 40 parts per thousand, pressure 0 to $1000 \mathrm{~kg} / \mathrm{cm}^{2}$, where 100 $\mathrm{kPa}=1.019716 \mathrm{~kg} / \mathrm{cm}^{2}$. For consistency, within the interactive version, the pressure must be input in $\mathrm{kPa}$.

Table:-1 Table of coefficients

\begin{tabular}{|ll|}
\hline Coefficients & Numerical Values \\
\hline C000 & 1402.392 \\
\hline CT1 & $0.5012285 \mathrm{E} 1$ \\
\hline CT2 & $-0.551184 \mathrm{E}-1$ \\
\hline CT3 & $0.221649 \mathrm{E}-3$ \\
\hline CS1 & $0.1329530 \mathrm{E} 1$ \\
\hline CS2 & $0.1288598 \mathrm{E}-3$ \\
\hline CP1 & 0.1560592 \\
\hline CP2 & $0.2449993 \mathrm{E}-4$ \\
\hline CP3 & $-0.8833959 \mathrm{E}-8$ \\
\hline CST & $-0.1275936 \mathrm{E}-1$ \\
\hline CT2P2 & $0.2656174 \mathrm{E}-7$ \\
\hline CTP2 & $-0.1593895 \mathrm{E}-5$ \\
\hline CTP3 & $0.5222483 \mathrm{E}-9$ \\
\hline CT3P & $-0.4383615 \mathrm{E}-6$ \\
\hline CS2P2 & $-0.1616745 \mathrm{E}-8$ \\
\hline CST2 & $0.9688441 \mathrm{E}-4$ \\
\hline CS2TP & $0.4857614 \mathrm{E}-5$ \\
\hline CSTP & $-0.3406824 \mathrm{E}-3$ \\
\hline
\end{tabular}

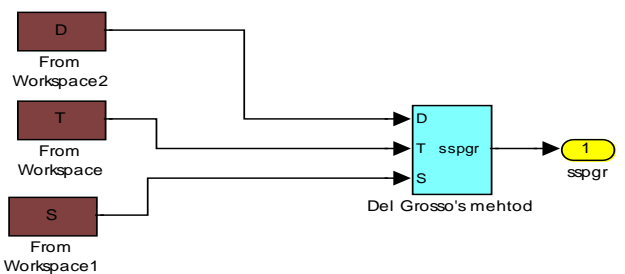

Fig.4. Simulation model subsystem for sound speed calculations based Del Grosso's method

Based on the above mathematical formula the simulation model for calculating sound speed in sea water has been developed as shown in fig 4 .

The sim model based on Del Grosso's ${ }^{[2]}$ method consists of following sub models as

\section{a) Del Grosso's main model b) Simin model}

The main model of sound speed based on Del Grosso's method is as shown in fig.5. It is designed by using input, output ,add, multiply and constant blocks. 


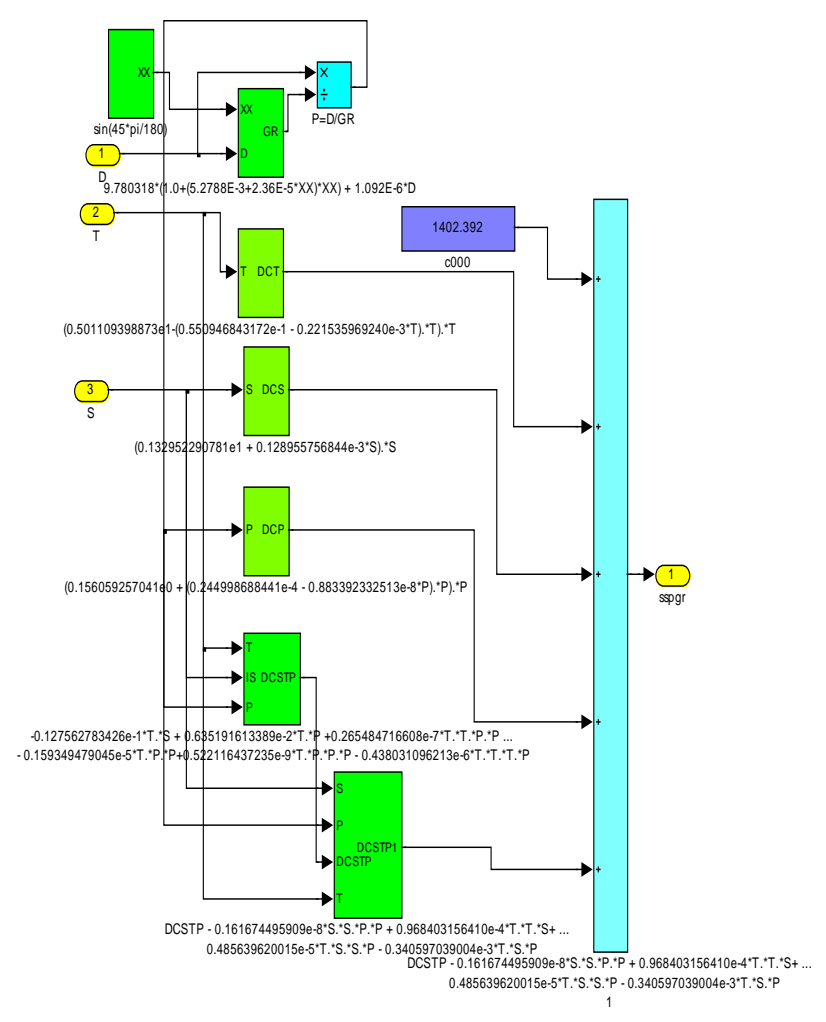

Fig.5 Del Grosso's main model.

This model consists of sub models which calculate the different parameters namely GR, DCT, DCP, DCS AND DCSTP.These parameters depend upon the sea water parameters. These calculations are based on the Del Grosso's equation.

\subsection{The UNESCO equation: Chen and Millero}

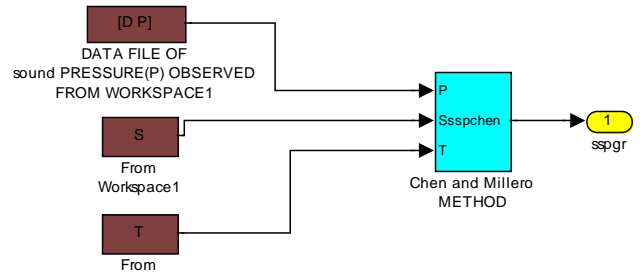

Fig.6 Main Simulation model for sound speed calculations based on Chen and Millero Method

International standard algorithm called the UNESCO algorithm, is due to Chen and Millero ${ }^{[3]}$ and has a more complicated form than the simple equations above, but uses pressure as a variable rather than depth. Wrong and Zhu have recalculated the coefficients in this algorithm following the adoption of the International Temperature Scale of 1990 and their form of the UNESCO equation is as follows.

$\begin{array}{ll}\mathrm{c}(\mathrm{S}, \mathrm{T}, \mathrm{P})= & \mathrm{Cw}(\mathrm{T}, \mathrm{P})+\mathrm{A}(\mathrm{T}, \mathrm{P}) \mathrm{S}+\mathrm{B}(\mathrm{T}, \mathrm{P}) \mathrm{S} 3 / 2+ \\ \mathrm{D}(\mathrm{T}, \mathrm{P}) \mathrm{S} 2 & \\ \mathrm{Cw}(\mathrm{T}, \mathrm{P})= & (\mathrm{C} 00+\mathrm{C} 01 \mathrm{~T}+\mathrm{C} 02 \mathrm{~T} 2+\mathrm{C} 03 \mathrm{~T} 3+\mathrm{C} 04 \mathrm{~T} 4 \\ & +\mathrm{C} 05 \mathrm{~T} 5)+(\mathrm{C} 10+\mathrm{C} 11 \mathrm{~T}+\mathrm{C} 12 \mathrm{~T} 2+\end{array}$

$\mathrm{C} 13 \mathrm{~T} 3+\mathrm{C} 14 \mathrm{~T} 4) \mathrm{P}+(\mathrm{C} 20+\mathrm{C} 21 \mathrm{~T}+\mathrm{C} 22 \mathrm{~T} 2$ $+\mathrm{C} 23 \mathrm{~T} 3+\mathrm{C} 24 \mathrm{~T} 4) \mathrm{P} 2+(\mathrm{C} 30+\mathrm{C} 31 \mathrm{~T}+$ $\mathrm{C} 32 \mathrm{~T} 2) \mathrm{P} 3$

$$
\begin{array}{ll}
\mathrm{A}(\mathrm{T}, \mathrm{P})= & (\mathrm{A} 00+\mathrm{A} 01 \mathrm{~T}+\mathrm{A} 02 \mathrm{~T} 2+\mathrm{A} 03 \mathrm{~T} 3+ \\
\mathrm{A} 04 \mathrm{~T} 4)+(\mathrm{A} 10+\mathrm{A} 11 \mathrm{~T}+\mathrm{A} 12 \mathrm{~T} 2+ \\
\mathrm{A} 13 \mathrm{~T} 3+\mathrm{A} 14 \mathrm{~T} 4) \mathrm{P}+(\mathrm{A} 20+\mathrm{A} 21 \mathrm{~T}+ \\
\mathrm{A} 22 \mathrm{~T} 2+\mathrm{A} 23 \mathrm{~T} 3) \mathrm{P} 2+(\mathrm{A} 30+\mathrm{A} 31 \mathrm{~T}+ \\
\mathrm{A} 32 \mathrm{~T} 2) \mathrm{P} 3
\end{array}
$$

$\mathrm{T}=$ temperature ${ }^{0} \mathrm{C} \quad \mathrm{S}=$ salinity parts per thousand $\mathrm{P}=$ pressure in bar Range of validity: temperature 0 to $40{ }^{\circ} \mathrm{C}$, salinity 0 to 40 parts per thousand, pressure 0 to 1000 bars.for consistency, within the interactive version, the pressure must be input in $\mathrm{kPa}$.

Table 2: Coefficients

\begin{tabular}{|ll|}
\hline Coefficients & Numerical values \\
\hline$C_{00}$ & 1402.388 \\
\hline$C_{01}$ & 5.03830 \\
\hline$C_{02}$ & $-5.81090 \mathrm{E}-2$ \\
\hline$C_{03}$ & $3.3432 \mathrm{E}-4$ \\
\hline$C_{04}$ & $-1.47797 \mathrm{E}-6$ \\
\hline$C_{05}$ & $3.1419 \mathrm{E}-9$ \\
\hline$C_{10}$ & 0.153563 \\
\hline$C_{11}$ & $6.8999 \mathrm{E}-4$ \\
\hline$C_{12}$ & $-8.1829 \mathrm{E}-6$ \\
\hline$C_{13}$ & $1.3632 \mathrm{E}-7$ \\
\hline$C_{14}$ & $-6.1260 \mathrm{E}-10$ \\
\hline$C_{20}$ & $3.1260 \mathrm{E}-5$ \\
\hline$C_{21}$ & $-1.7111 \mathrm{E}-6$ \\
\hline$C_{22}$ & $2.5986 \mathrm{E}-8$ \\
\hline$C_{23}$ & $-2.5353 \mathrm{E}-10$ \\
\hline$C_{24}$ & $1.0415 \mathrm{E}-12$ \\
\hline$C_{30}$ & $-9.7729 \mathrm{E}-9$ \\
\hline$C_{31}$ & $3.8513 \mathrm{E}-10$ \\
\hline$C_{32}$ & $-2.3654 \mathrm{E}-12$ \\
\hline$A_{00}$ & 1.389 \\
\hline$A_{01}$ & $-1.262 \mathrm{E}-2$ \\
\hline
\end{tabular}

The detail sim model of sound speed based on the UNESCO equation is as shown in fig. 6 .

This model has been developed by using constant data, input, and output multiply and adds blocks.

\subsection{Coppens Method}

The equation for the speed of sound in sea-water as a function of temperature (T), salinity(S) and depth (D) given by Coppens is ;

$$
\begin{gathered}
\mathrm{c}(\mathrm{D}, \mathrm{S}, \mathrm{t})=\mathrm{c}(0, \mathrm{~S}, \mathrm{t})+(16.23+0.253 \mathrm{t}) \mathrm{D}+(0.213-0.1 \mathrm{t}) \mathrm{D} 2+ \\
{[0.016+0.0002(\mathrm{~S}-35)](\mathrm{S}-35) \mathrm{t} .}
\end{gathered}
$$

Where c $(0, S, t)$ is given as

$\mathrm{c}(0, \mathrm{~S}, \mathrm{t})=1449.05+45.7 \mathrm{t}-5.21 \mathrm{t} 2+0.23 \mathrm{t} 3+(1.333-0.126 \mathrm{t}+$ $0.009 \mathrm{t} 2)(\mathrm{S}-35)$. 
$\mathrm{t}=\mathrm{T} / 10, \mathrm{~T}=$ temperature

$\mathrm{D}=$ depth in kilometers.

Range of validity: temperature 0 to $35{ }^{\circ} \mathrm{C}$, salinity 0 to 45 parts per thousand, depth 0 to $4000 \mathrm{~m}$. The main simulation model based on Coppens equation is as shown in fig. 7 .

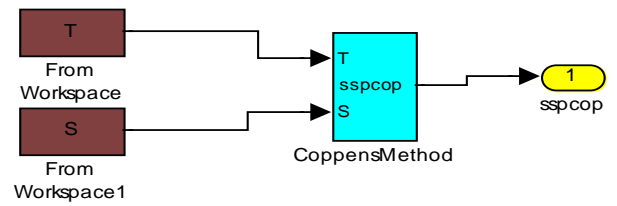

Fig.7. Main Simulation model calculates the sound speed in the sea water based on Coppens Method

\subsection{R. E. Francois and G. R. Garrison Equation}

The equation derived for speed of sound in sea water by R. E. Francois and Garrison is quit simple. It is based on all the sea water parameters. It is written as

$$
\mathrm{C}=1415.5+3.21 \mathrm{~T}+1.19 \mathrm{~S}+0.0167 \mathrm{D}
$$

The main simulation model which determines the speed of sound based on Francois and Garrison equation is as shown in fig.8.

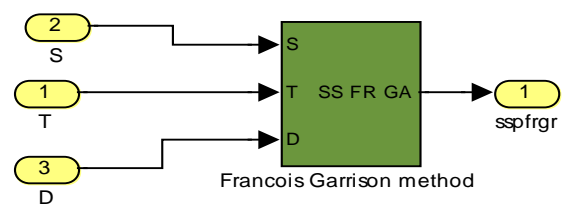

Fig.8. Main Simulation model of sound speed based on Francois and Garrison equation.

\section{RESULTS}

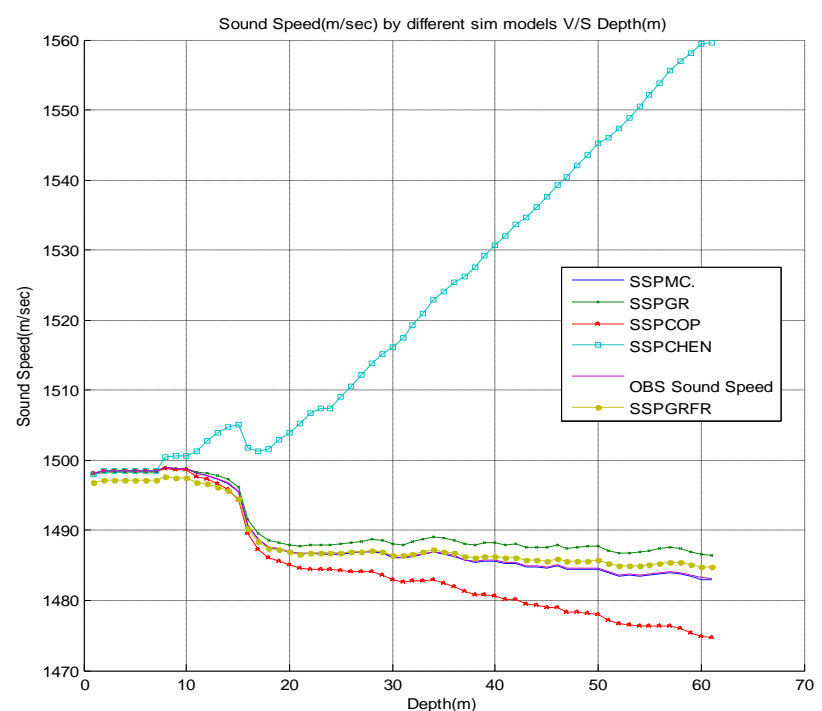

Fig.9. Sound speed (m/sec) v/s Depth (m)

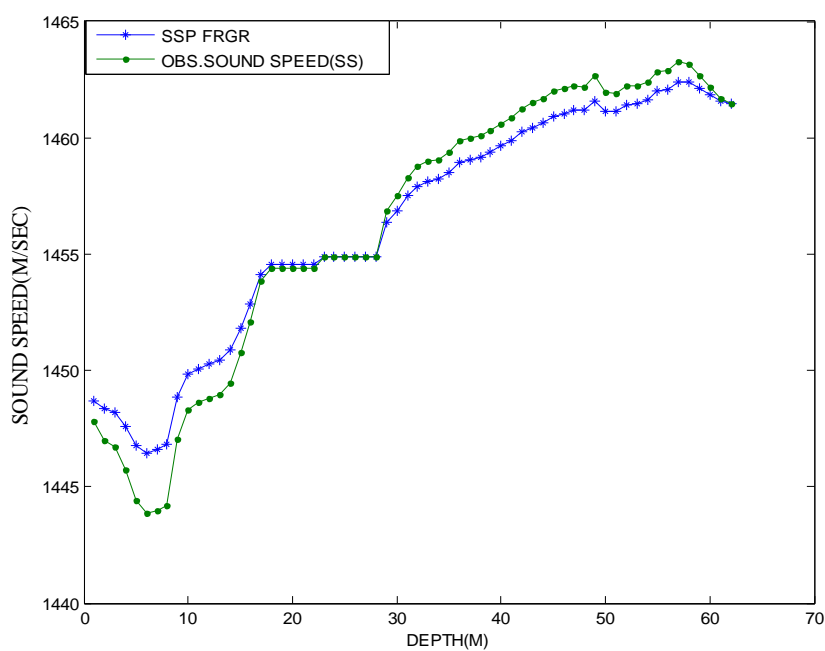

Fig. 10 Sound speed $(\mathrm{m} / \mathrm{sec})$ by FRGR V/S Depth (m)

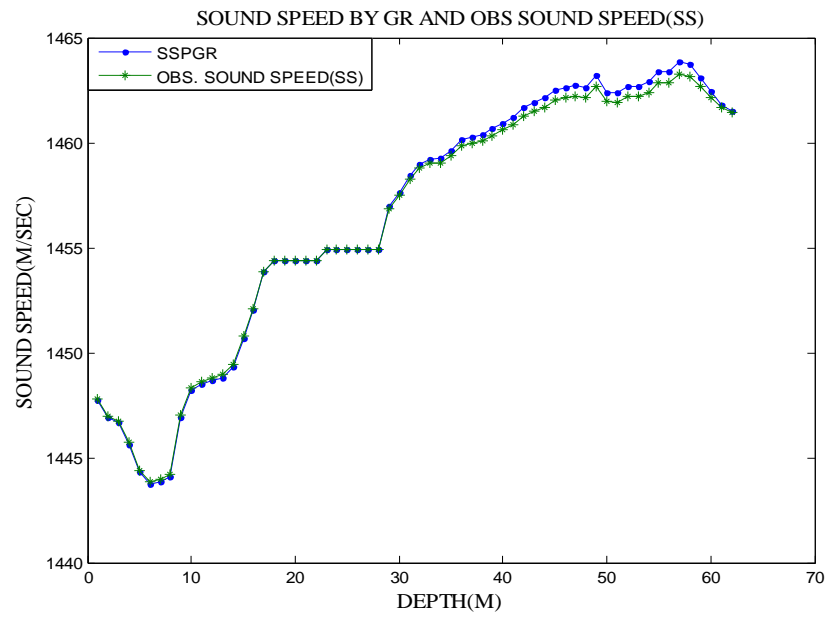

Fig.11. Sound speed $(\mathrm{m} / \mathrm{sec})$ by PMC V/S Depth (m)

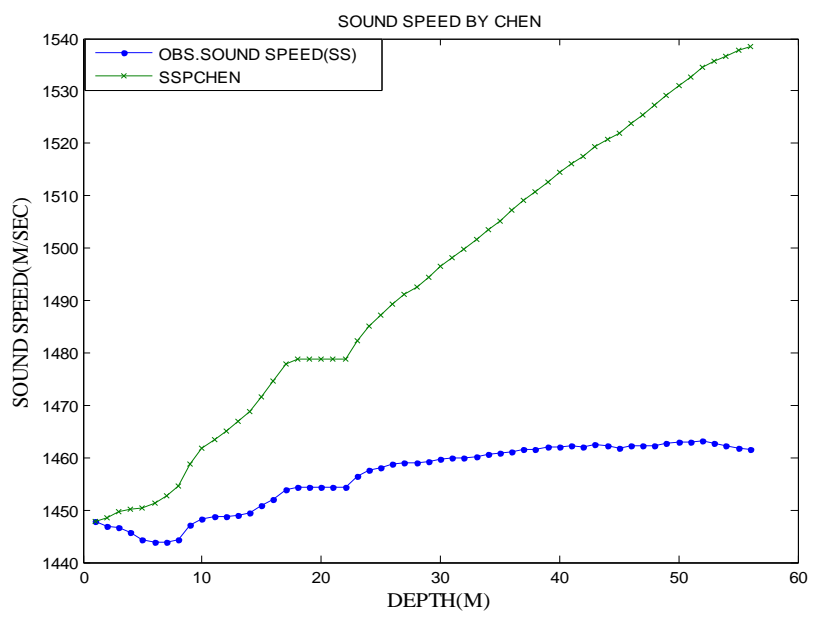

Fig.12. Sound speed $(\mathrm{m} / \mathrm{sec})$ by CHEN V/S Depth (m) 


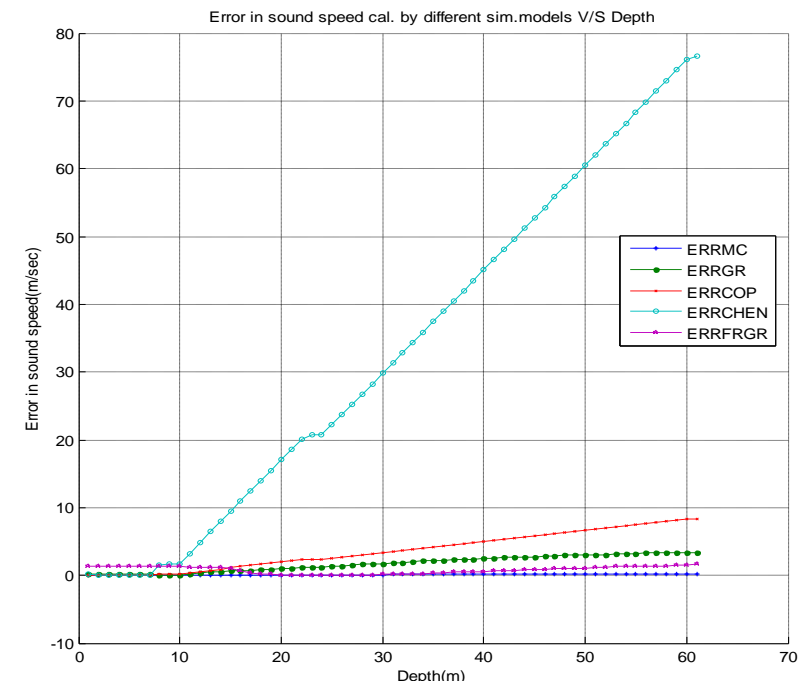

Fig. 13.Error in Sound speed $(\mathrm{m} / \mathrm{sec})$ V/S Depth (m)

It is seen that the deviation in the sound speed due to method by Chen ${ }^{(6)}$ et al goes on increasing with the increase in the depth. The model developed using Coppens ${ }^{(11)}$ also gives deviation which tends to increase for larger depths. There is a close agreement between the speeds evaluated using other models developed. The fig. 9 shows the simulation results. The error is least in the model developed using Mackenzie Equation. Figures 10 to 12 show the comparative study of the sound speeds by different models with the observed sound speed

\section{CONCLUSION}

Five different simulation models have been developed to determine the speed of sound speed in sea water by inputting the sea water parameter data. It is seen that in all the models except Chen and Millero model the speeds evaluated using the simulation models developed match satisfactorily with the observed speed of sound in sea water. Deviation exists and it tends to increase with the depth. The errors in the fig. 13 reveal that except for the Chen and Millero model the errors from different models are within acceptable margin. The Mackenzie Equation model gives least error.

\section{ACKNOWLEDGEMENTS}

The authors are thankful to the National Institute of Oceanography (NIO) Goa, India for providing the practical data of whole year of Arabian Sea water.

\section{REFERENCES}

[1] MATLAB software user manual, Math works Inc.

[2] Del Grosso, "A New Equation for the speed of sound in Natural Waters", J. Acoust. Soc. Am. 564 (1974).

[3] Chen and Millero, "The Sound Speed in Seawater", J. Acoust. Soc. Am. 62 (1977), 1129-1135 Derivatives of the EOS80 equation of state for seawater and the adiabatic lapse rate.

[4] Mackenzie, K.V. "Nine-term Equation for Sound Speed in the Oceans", J. Acoust. Soc. Am. 70 (1981), 807-812.

[5] N.P. Fofonoff and R.C. Millard Jr "Algorithms for computation of fundamental properties of seawater" (1983), UNESCO technical papers in marine science. No. 44, Division of Marine Sciences. UNESCO, Place de Fontenoy, 75700 Paris.

[6] C-T. Chen and F.J. Millero, "Speed of sound in seawater at high pressures" (1977) J. Acoust. Soc. Am. 62(5) pp $1129-1135$

[7] B.D. Dushaw, P.F. Worcester, B.D. Cornuelle and B.M. Howe, "On equations for the speed of sound in sea water” (1993) J. Acoust. Soc. Am. 93(1) pp 255-275

[8] Thomas J. Hayward and T.C.Yang"Underwater acoustic communication Channel Capacity: A simulation study". Naval Research Laboratory, Washinton DC20375.

[9] G.V. Krishna Kumar and P.Balasubramanian "I WAVE: an ocean simulation model for internal wave" Naval Physical and Oceanographic Laboratory, Thrikkakara, Kochi 682021, India.

[10] Ahcene Bouzoualegh, Thierry Val, "Modelling and Simulation of Underwater Acoustics Communication based on State flow and Simulink Models." $3^{\text {rd }}$ International Conference: Science of Electronic, Techonologies of Information and Telecommunications March 27-31 2005-TUNISIA

[11] A.B. Coppens, "Simple equations for the speed of sound in Neptunian waters" (1981) J. Acoust. Soc. Am. 69(3), pp 862-863

[12] V.A. Del Grosso, "New equation for the speed of sound in natural waters" (with comparisons to other equations) (1974) J. Acoust. Soc. Am 56(4) pp1084-1091. 